\title{
KUALITAS PENGAWASAN KEUANGAN DAERAH \\ DI INSPEKTORAT PROPINSI JAWA TENGAH
}

\author{
Oleh : \\ Setyo Mahanani \\ Dosen Fakultas Ekonomi \\ Universitas Wahid Hasyim Semarang
}

\begin{abstract}
This study aims to strengthen objectivity, expertise, professional skills and compliance with the code of ethics on the quality of the inspectorate apparatus. A common problem in this studywas the continued increase in state losses caused by corruption and the like. The research sample was taken at the inspectorate of Central Java province. Data were analyzed using Partial Lease Square with SmartPLS 03 software. The results showed objectivity and adherence to the code of ethics of reproduction to the quality of examination, while the expertise and professional skill were not significant on the quality of the examination. The value of things that are jointly shared objectivity, expertise, professional skills and adherence to the code of ethics provide quality to audit quality of $56.4 \%$ while the remaining $45.6 \%$ by other factor outside the construct. The implication of this research findings for the importance of quality audit is the need for objective attitude of the auditor in addition to the effort to increase the ethical value through coaching and training.
\end{abstract}

Keywords: quality of inspection, objectivity, expertise, professional skills, adherence to the code of ethics.

\section{PENDAHULUAN}

Pengawasan intern merupakan seluruh proses kegiatan pengawasan, reviu, pemantauan, evaluasi, dan kegiatan pengawasan lainnya berupa asistensi, sosialisasi dan konsultansi terhadap penyelenggaraan tugas dan fungsi organisasi untuk memberikan keyakinan yang memadai bahwa suatu kegiatan telah dilaksanakan sesuai dengan tolok ukur yang telah ditetapkan secara efektif dan efisien untuk mewujudkan kepemerintahan yang baik (Peraturan Menteri Negara Pendayagunaan Aparatur Negara nomor PER/05/M.PAN/03/2008. Tentang Standar Audit Aparat Pengawasan Intern Pemerintah). Elder, et al (2013) mendefinisikan audit sebagai pengumpulan dan evaluasi bukti mengenai informasi untuk menentukan dan melaporkan derajat kesesuaian antara informasi tersebut dengan kriteria yang telah ditetapkan. 
Auditing internal adalah suatu aktivitas konsultasi yang independen, obyektif yang di desain untuk menambah nilai dan meningkatkan operasi suatu organisasi. Auditing internal membantu organisasi mencapai tujuannya dengan membawa pendekatan sistematis, disiplin utnuk mengevaluasi dan meningkatkan efektivitas proses manajemen risiko, pengendalian dan tata kelola (Missier,et al. 2014). Menurut Mardiasmo, (2005) terdapat tiga aspek utama yang mendukung terciptanya kepemerintahan yang baik (good governance) yaitu pengawasan, pengendalian dan pemeriksaan. Pemeriksaan (audit) merupakan kegiatan yang dilakukan oleh pihak yang memiliki independensi dan kompetensi professional untuk memeriksa apakah hasil kinerja pemerintah telah sesuai dengan standar yang telah ditetapkan. Akuntabilitas publik berhubungan dengan praktik transparansi dan pemberian informasi kepada publik dalam rangka pemenuhan hak publik.

Fenomena yang masih sering terjadi Propinsi Jawa Tengah adalah banyaknya kasus korupsi, penyalahgunaan wewenang dan jabatan, pelanggaranpelanggaran dan masih banyak kasus pidana lainnya. Sindonews.com memberitakan beberapa kasus kurupsi, pelanggaran atau penyalahgunaan jabatan yang dilakukan oleh aparat pemerintah seperti : kasus korupsi dana hibah Komite Olah raga Nasional Indonesia (KONI) cabang Semarang periode 2012-2013, yang merugikan negara sebesar Rp 2 Miliar (Kamis,9/2/2015); kasus korupsi dana bansos Pemprov di Rembang yang merugikan keuangan negara sebesar Rp 654.000.000,- (Selasa, 14 April 2015); kasus proyek asrama Kemenhub di Tegal yang merugikan keuangan negara sebesar Rp 1,7 miliar (Rabu, 2 April 2015); korupsi kepala bidang pengairan Dinas Pekerjaan Umum (DPU) Kabupaten Rembang yang merugikan keuangan negara sebesar Rp 750.000.000,- dan masih banyak lagi kasus-kasus yang telah dilakukan oleh aparat pemerintah.

Mengingat fenomena yang terjadi pada pemerintah daerah Propinsi Jawa Tengah maka penting untuk menegakkan pemeriksaan yang berkualitas demi mewujudkan pemerintahan yang akuntabel dan transparan. Dengan pertimbangan tersebut maka peneliti bermaksud melakukan penelitian pada aparat inspektorat yang mengkaji tentang pengaruh independensi, obyektivitas, keahlian, kecermatan profesional dan kepatuhan pada kode etik terhadap kualitas audit. 


\section{LANDASAN TEORI}

\section{Kualitas Pengawasan}

Hakekat pengawasan adalah mencegah sedini mungkin terjadinya penyimpangan, pemborosan, penyelewengan, hambatan, kesalahan, kegagalan dalam pencapaian tujuan dan pelaksanaan tugas-tugas suatu organisasi. Pengawasan intern adalah seluruh proses kegiatan audit, reviu, pemantauan, evaluasi, dan kegiatan pengawasan lainnya berupa asistensi, sosialisasi dan konsultansi terhadap penyelenggaraan tugas dan fungsi organisasi dalam rangka memberikan keyakinan yang memadai bahwa kegiatan telah dilaksanakan sesuai dengan tolok ukur yang telah ditetapkan secara efektif dan efisien untuk kepentingan pimpinan dalam mewujudkan kepemerintahan yang baik (Peraturan Menteri Negara Pendayagunaan Aparatur Negara nomor PER/05/M.PAN/03/2008). Standar audit menjadi bimbingan dan ukuran kualitas kinerja aditor (Messier et al, 2014). Menurut pengukuran kualitas pengawasan atas laporan keuangan, khususnya yang dilakukan oleh APIP, wajib menggunakan Standar Pengawasan Keuangan Negara (SPKN). Pernyataan tersebut tertulis dalam lampiran 3 SPKN yang menegaskan bahwa "Besarnya manfaat yang diperoleh dari pekerjaan pengawasan tidak terletak pada temuan pengawasan yang dilaporkan atau rekomendasi yang dibuat, tetapi terletak pada efektivitas penyelesaian yang ditempuh oleh entitas yang diperiksa. Pengawasan yang berkualitas adalah Pengawasan yang dapat ditindaklanjuti oleh pengawas. Kualitas ini harus dibangun sejak awal pelaksanaan Pengawasan hingga pelaporan dan pemberian rekomendasi. Dengan demikian, indikator yang digunakan untuk mengukur kualitas pengawasan antara lain kualitas proses, apakah pengawasan dilakukan dengan cermat, sesuai prosedur, sambil terus mempertahankan sikap skeptis.

\section{Obyektivitas}

Obyektifitas pengawas diperlukan agar kredibilitas hasil pekerjaan APIP meningkat. Penilaian independensi dan obyektifitas mencakup dua komponen, yaitu status APIP dalam organisasi dan kebijakan untuk menjaga obyektifitas pengawas terhadap obyek pengawasan (Peraturan Menteri Negara Pendayagunaan Aparatur Negara nomor PER/05/M.PAN/03/2008 tentang "Standar Pengawasan Aparat Pengawasan Intern Pemerintah". Pusdiklatwas BPKP (2005), menyatakan 
obyektifitas sebagai bebasnya seseorang dari pengaruh pandangan subyektif pihakpihak lain yang berkepentingan, sehingga dapat mengemukaan pendapat menurut apa adanya. Unsur perilaku yang menunjang obyektifitas antara lain (1) dapat diandalkan dan dipercaya, (2) tidak merangkap sebagai panitia tender, kepanitiaan lain dan atau pekerjaan-pekerjaan lain yang merupakan tugas operasional obyek yang diperiksa, (3) Tidak berangkat tugas dengan niat untuk mencari-cari kesalahan orang lain, (4) dapat mempertahankan kriteria dan kebijaksanaan-kebijaksanaan yang resmi, serta (5) dalam bertindak maupun mengambil keputusan didasarkan atas pemikiran yang logis.

\section{Keahlian}

Berdasarkan peraturan menteri negara pemberdayaan aparatur negara N0.Per/05/M.Pan.03/2008 tanggal 31 Maret 2008 menyatakan bahwa pengawas harus mempunyai pengetahuan, ketrampilan dan kompetensi lainnya yang diperlakukan untuk melaksanakan tugas dan tanggung jawabnya. Pimpinan APIP harus yakin bahwa latar belakang kompetensi teknis dan pendidikan pengawasmemadai untuk pekerjaan pengawas yang akan di amanatkan. Dengan demikian pimpinan APIP harus menetapkan spesifikasi yang memadai mengenai kompetensi teknis dan pendidikan dalam mengisi posisi pengawasdi lingkungan APIP. Keahlian (kompetensi) seorang pengawasdibidang pengawasaning ditunjukkan oleh latar belakang pendidikan dan pengalaman yang dimilikinya. Dari sisi pendidikan, idealnya seorang pengawas memiliki latar belakang pendidikan dibidang pengawasan. Sedangkan pengalaman, lazimnya ditunjukkan oleh lamanya yang bersangkutan berkarir di bidang pengawasan.

\section{Kecermatan Profesional}

Pengawas harus menjaga pengetahuan dan keterampilan profesional mereka dalam tingkat yang cukup tinggi dan tekun dalam menerapkan pengetahuan dan keterampilan mereka ketika memberikan jasa profesional. Sehingga, para pengawasharus menahan diri dari memberikan jasa yang mereka tidak memiliki kompetensi dalam menjalankan tugas tersebut, dan harus menjalankan tugas profesional mereka sesuai dengan seluruh standar teknis dan profesi (Elder, 2013). Dalam melaksanakan tugasnya, pengawas harus menggunakan keahliannya dengan cermat (due professional care), direncanakan dengan baik, menggunakan pendekatan 
yang sesuai, serta memberikan pendapat berdasarkan bukti yang cukup dan ditelaah secara mendalam.

\section{Kepatuhan pada Kode Etik}

Pelaksanaan pengawasan harus mengacu kepada Standar Pengawasan yang ditetapkan oleh peraturan menteri negara pemberdayaan aparatur negara N0.Per/05/M.Pan.03/2008, dan pengawas wajib mematuhi Kode Etik yang merupakan bagian yang tidak terpisahkan dari Standar Pengawasan tersebut. Kode etik yang dibuat bertujuan untuk mengatur hubungan antara dengan : rekan kerjanya, atasannya, obyek pengawasnya,dan dengan masyarakat. Kode Etik penting bagi pengawas internal karena keterangan dalan pekerjaan mereka bergantung pada reputasi obyektivitas dan integritas personal yang tinggi. Kode etik menspesifikasi empat prinsip utama perilaku etis dan sejumlah aturan terasosiasi yang mendukung perilaku yang diekspektasi dari anggota Institute for Internal Auditor, yaitu integritas, obyektivitas, kerahasiaan dan kompetensi (Messier, 2014)

\section{Model Konseptual Penelitian}

Model konseptual dalam penelitian ini dapat digambarkan sebagai berikut:

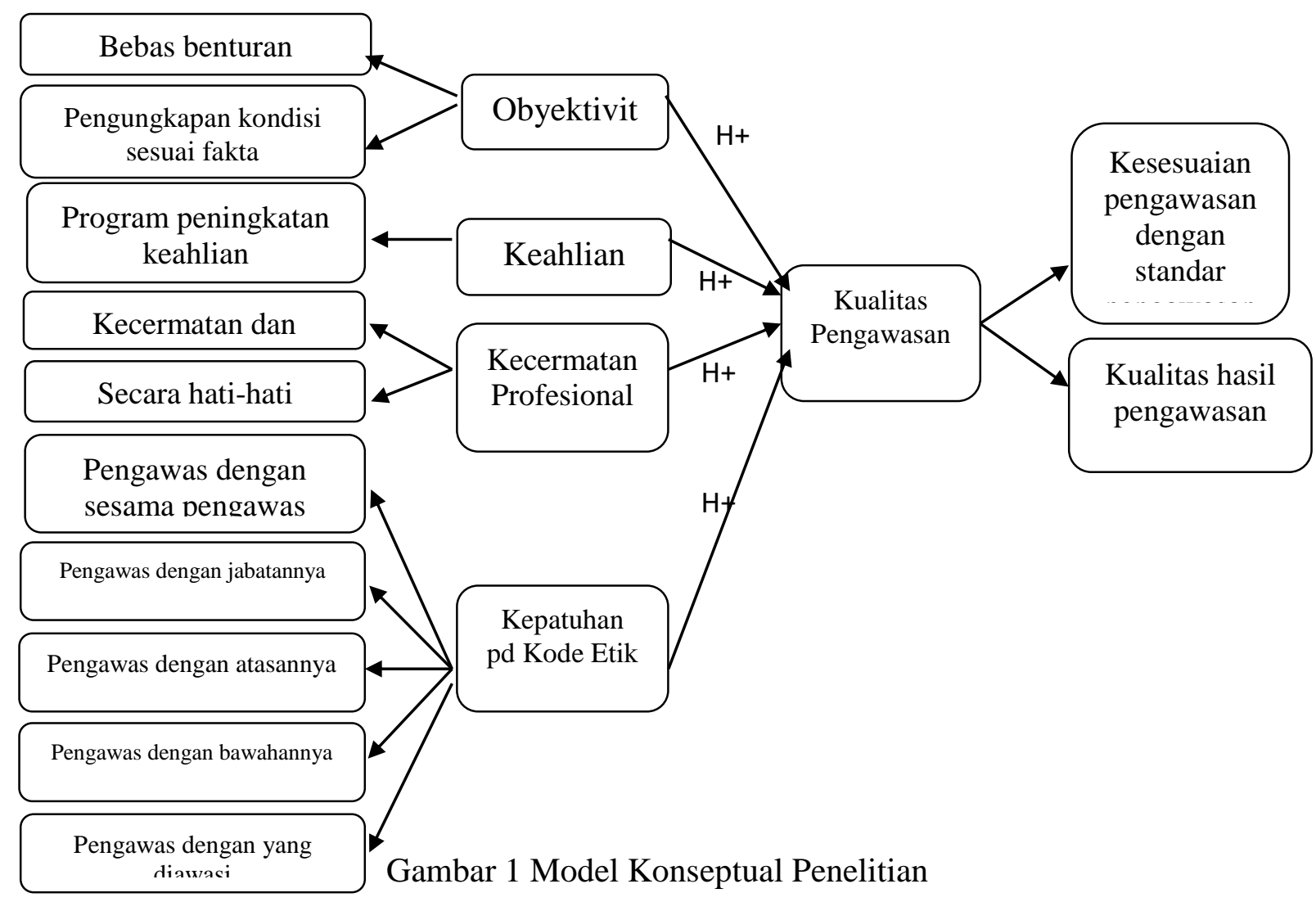




\section{Pengembangan Hipotesis}

\section{Pengaruh obyektivitas terhadap kualitas pengawasan inspektorat}

Menurut Peraturan Badan Pengawasan Keuangan Republik Indonesia Nomor 01 Tahun 2007 tentang Standar Pengawasan Keuangan Negara, bersikap obyektif merupakan cara berpikir yang tidak berpihak, jujur secara intelektual, dan bebas dari benturan kepentingan. Obyektivitas diperlukan oleh seorang pengawas agar mampu bertindak adil tanpa dipengaruhi tekanan ataupun permintaan dari pihak tertentu yang berkepentingan atas hasil pengawasan (Sukriah, 2009). Obyektifitas sebagai bebasnya seseorang dari pengaruh pandangan subyektif pihak-pihak lain yang berkepentingan.

Penelitian mengenai obyektivitas sudah pernah dilakukan sebelumnya. Havidz (2010); Sukriah, etal (2009) dan Arianti et al., (2014), hasil penelitiannya menunjukan bahwa obyektivitas berpengaruh secara positif terhadap kualitas hasil pengawasan. Hal ini menunjukkan bahwa semakin tinggi tingkat obyektivitas pengawasmaka semakin baik kualitas pengawasan yang dihasilkan oleh inspektorat. Berdasarkan hal tersebut diatas, hipotesis kedua yang diajukan adalah:

\section{$\mathrm{H}_{1}$ : Obyektivitas berpengaruh positif terhadap kualitas pengawasan Inspektorat.}

\section{Pengaruh keahlian terhadap kualitas pengawasan inspektorat}

Keahlian pengawas adalah kemampuan pengawas untuk mengaplikasikan pengetahuan dan pengalaman yang dimilikinya dalam melakukan pengawasan sehingga pengawas dapat melakukan pengawasan dengan teliti, cermat, intuitif, dan obyektif. Oleh karena itu, dapat dipahami bahwa pengawasan harus dilaksanakan oleh orang yang memiliki keahlian dan pelatihan teknis cukup sebagai pengawas. Dengan demikian, pengawas belum memenuhi persyaratan jika tidak memiliki pendidikan dan pengalaman yang memadai dalam bidang pengawasan.

Lubis (2009) telah melakukan penelitian mengenai pengaruh keahlian terhadap kualitas pengawasan, dimana keahlian diproksikan dengan pengalaman dan pengetahuan, sedangkan independensi diproksikan dalam lama ikatan 
dengan klien, tekanan dari klien dan telaah dari rekan. Hasil penelitiannya menunjukkan bahwa keahlian pengawasberpengaruh terhadap kualitas pengawasan. Dengan demikian, dapat dikemukakan hipotesis sebagai berikut:

\section{H2: Keahlian Pengawas berpengaruh positif terhadap kualitas pengawas}

\section{Pengaruh kecermatan profesional terhadap kualitas pengawasan aparat}

Kecermatan profesional merupakan faktor yang keempat. Kecermatan profesional dalam penelitian ini adalah bahwa pengawasharus menggunakan keahlian profesionanya dengan cermat dan seksama (due professional care) dan secara hati-hati (prudent) dalam setiap penugasan. Due professional care dapat diterapkan dalam pertimbangan profesional (professional judgement), meskipun dapat saja terjadi penarikan kesimpulan yang tidak tepat ketika pengawasan sudah dilakukan dengan seksama.

Lubis (2009) telah pelakukan penelitian tentang pengaruh kecermatan profesional pengawas terhadap kualitas pengawas inspektorat. Hasil penelitian menunjukkan bahwa kecermatan profesional berpengaruh positif terhadap kualitas pengawasanor. Sehingga dengan kata lain, semakin baik kecermatan profesional seorang pengawas maka akan semakin baik pula kualitas pengawas yang dihasilkan. Dengan demikian, dapat dikembangkan hipotesis sebagai berikut:

\section{H3 : Kecermatan profesional berpengaruh positif terhadap kualitas pengawas}

\section{Pengaruh kepatuhan pada kode etik terhadap kualitas pengawasan aparat}

Pengawasharus mematuhi Kode Etik yang ditetapkan. Pelaksanaan pengawasan harus mengacu kepada Standar Pengawasan ini, dan pengawaswajib mematuhi Kode Etik yang merupakan bagian yang tidak terpisahkan dari Standar Pengawasan tersebut. Pemahaman mengenai kode etik akan mengarah kepada tatanan pola pikir, perilaku dan sikap para pejabat pengawas masyarakat untuk menjaga martabat supaya mendapat tempat yang terhormat dan mampu memberikan hasil pengawasan yang diharapkan.

Pengaruh kepatuhan pada kode etik terhadap kualitas pengawasan aparat pernah diteliti oleh Lubis, (2009). Hasil penelitian menunjukkan bahwa kepatuhan 
pada kode etik berpengaruh positif terhadap kualitas hasil pengawasan. Dengan demikian dengan kepatuhan kode etik yang tinggi maka mendukung kualitas pengawasan akan lebih baik. Dari paparan diatas dapat dikembangkan hipotesis sebagai berikut:

\section{H4 : Kepatuhan pada kode etik berpengaruh positif terhadap kualitas pengawasan Inspektorat.}

\section{METODE PENELITIAN}

\section{Populasi dan Sampel Penelitian}

Data yang digunakan dalam penelitian ini adalah data primer. Data primer adalah data yang langsung dicari sendiri oleh peneliti pada saat penelitian di lapangan. Data primer diperoleh dengan menggunakan daftar pertanyaan (kuesioner) yang telah terstruktur dengan tujuan untuk mengumpulkan informasi dari pengawas Inspekorat kabupaten/kota di karesidenan Semarang dan inspektorat propinsi Jawa Tengah sebagai responden dalam penelitian ini.

Penelitian ini menggunakan kuesioner yang terdiri dari lima bagian. Antara lain : bagian pertama berisikan sejumlah pertanyaan yang berhubungan dengan obyektivitas pengawas, bagian kedua berisikan sejumlah pertanyaan yang berhubungan dengan keahlian pengawas, bagian ketiga berisikan sejumlah pertanyaan yang berhubungan dengan kecermatan profesional pengawas, bagian keempat berisikan sejumlah pertanyaan yang berhubungan dengan kepatuhan pada kode etik pengawas, bagian kelima berisikan sejumlah pertanyaan yang berhubungan dengan kualitas pengawasan inspektorat. Kuesioner yang dikirimkan disertai dengan surat permohonan serta penjelasan tentang tujuan penelitian yang dilakukan.

Sampel dalam penelitian ini terdiri dari Pengawas Inspektorat propinsi Jawa Tengah dan pengawas inspektorat kabupaten/kota di karesidenan Semarang. Pengawas inspektorat Provinsi Jawa Tengah sebanyak 32 orang, dan inspektorat daerah di karesidenan semarang antara lain: Pengawas inspektorat Kota Semarang sebanyak 7 orang, Pengawas inspektorat Kabupaten Semarang sebanyak 13 orang, Pengawas inspektorat Kabupaten Demak sebanyak 13 orang, Pengawas inspektorat Kabupaten Kendal sebanyak 22 orang dan Pengawas inspektorat Kota Salatiga sebanyak 5 orang. Sehingga 
jumlah sampel yang diambil dalam penelitian ini adalah sebanyak 92 responden.

\section{Analisis Data dan Pengujian Hipotesis}

Dari analisis data menggunakan Partial Least Square (PLS) diperoleh hasil PLS Algorithm sebagai berikut :

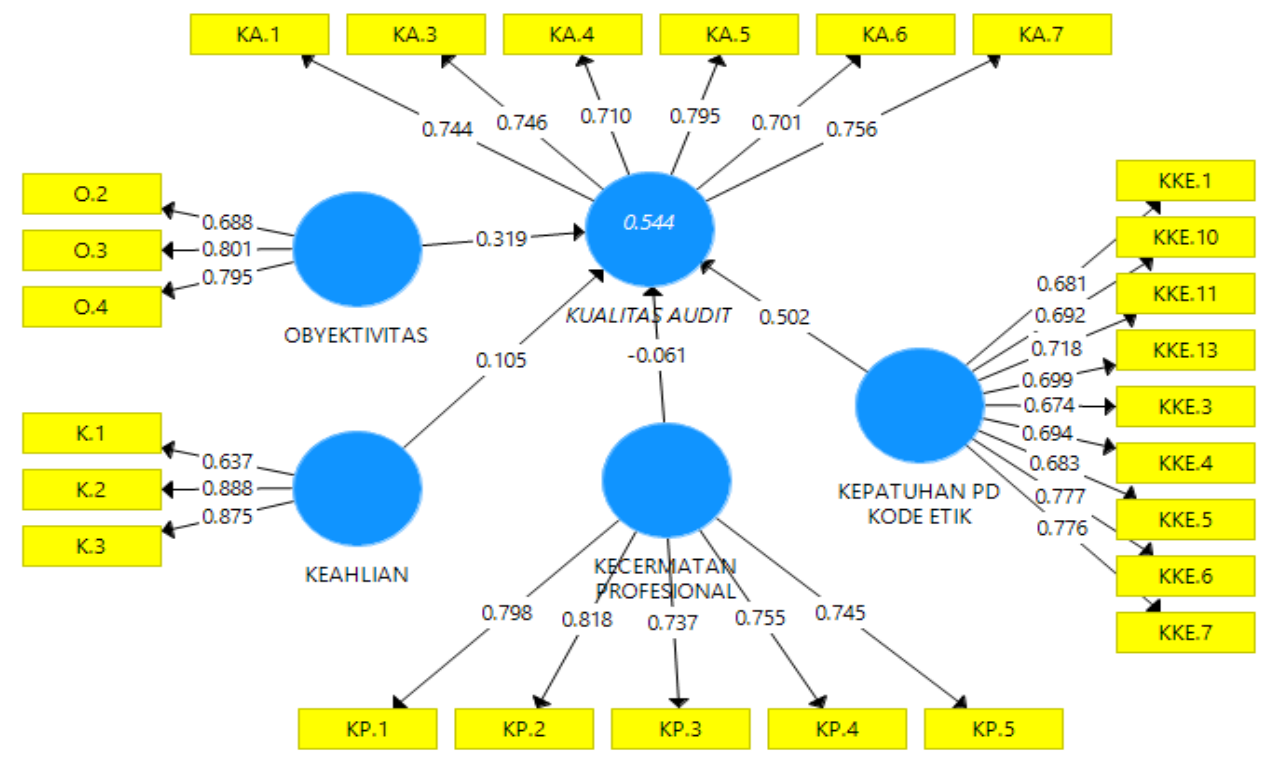

Gambar 2. Tampilan Hasil PLS Algorithm Tahap Awal

Teknik pengolahan data menggunakan metode SEM berbasis Partial Least Square (PLS) memerlukan 2 tahap untuk menilai Fit Model dari sebuah model penelitian (Ghozali, 2012). Tahap-tahap tersebut yaitu menilai outer model dan inner model. Outer model dan inner model.

\section{Model Analisis Persamaan Struktural Tahap Akhir}

Model analisis persamaan struktural menjelaskan hubungan antara variabel dan item. Penelitian ini terdapat dua variabel independen dan satu variabel dependent. Variabel independen terdiri dari Obyektivitas, Keahlian, Kecermatan Profesional dan Kepatuhan pada Kode Etik. Variabel dependen yaitu Kualitas Pengawasan. Gambar 2 menjelaskan model persamaan analisis struktural Akhir. 


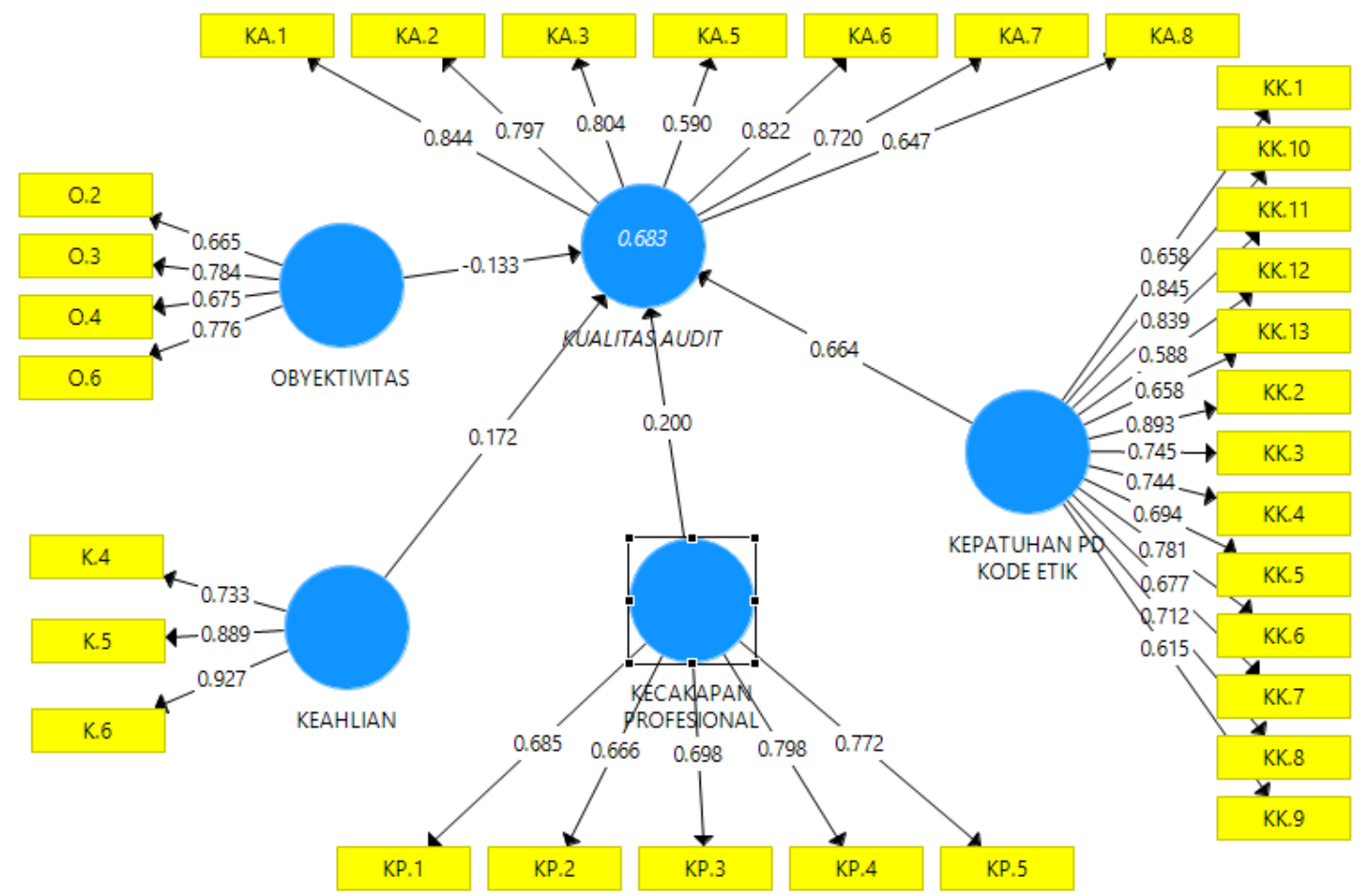

Gambar 3. Model Persamaan Analisis Struktural Tahap Akhir

Berdasarkan hasil output analisis Outer Model Tahap akhir, semua Crosss loading item indicator sudah di atas 0,5. Berikut disajikan ringkasan hasil Outer Model Tahap akhir.

Tabel 2

Evaluasi Outer Model Tahap Akhir

\begin{tabular}{|c|c|c|c|c|}
\hline $\begin{array}{c}\text { Convergen } \\
\text { Validity }\end{array}$ & Variabel & AVE & $\begin{array}{c}\text { Nilai } \\
\text { Kritis }\end{array}$ & Kriteria \\
\hline & Objektivitas $(\mathrm{O})$ & 0,529 & \multirow{5}{*}{$>0,5$} & Valid \\
\hline & Keahlian $(\mathrm{K})$ & 0,729 & & Valid \\
\hline & Kecermatan Profesional (KP) & 0,526 & & Valid \\
\hline & Kepatuhan pd Kode Etik (KKE) & $\mathbf{0 , 5 3 6}$ & & Valid \\
\hline & Kualitas Pengawasan (KA) & 0,565 & & Valid \\
\hline \multicolumn{5}{|c|}{ Cronbach alpha } \\
\hline & Objektivitas $(\mathrm{O})$ & 0,729 & \multirow{5}{*}{$>0,7$} & Reliabel \\
\hline & Keahlian (K) & $\mathbf{0 , 8 3 1}$ & & Reliabel \\
\hline & Kecermatan Prof (KP) & $\mathbf{0 , 7 7 7}$ & & Reliabel \\
\hline & Kepatuhan pd KE (KKE) & 0,926 & & Reliabel \\
\hline & Kualitas Pengawasan (KA) & 0,869 & & Reliabel \\
\hline \multicolumn{5}{|c|}{ Composite Realiability } \\
\hline & Objektivitas $(\mathrm{O})$ & $\mathbf{0 , 8 1 7}$ & \multirow{5}{*}{$>0,7$} & Reliabel \\
\hline & Keahlian (K) & $\mathbf{0 , 8 8 9}$ & & Reliabel \\
\hline & Kecermatan Prof (KP) & $\mathbf{0 , 8 4 7}$ & & Reliabel \\
\hline & Kepatuhan pd KE (KKE) & $\mathbf{0 , 9 3 7}$ & & Reliabel \\
\hline & Kualitas Pengawasan (KA) & 0,900 & & Reliabel \\
\hline
\end{tabular}

Sumber: Data Primer Diolah, 2016 
Berdasarkan hasil output analisis Outer Model Tahap akhir, semua nilai Cross loading item indikator sudah > 0,5; Convergent Validity sudah > 0,5; dan koefisien reliabilitas (Cronbach alpha dan Composite Realiability) semua konstruk sudah di atas 0,7.Sehingga dapat dilanjutkan ke Analisis Model Struktural (Inner Model).

Tabel 3.

Evaluasi Model Struktural (Inner Model)

\begin{tabular}{|l|r|}
\hline \multicolumn{1}{|c|}{ VARIABEL EKSOGEN } & \multicolumn{2}{|c|}{$\begin{array}{c}\text { VAR. ENDOGEN } \\
\text { (KUPENGAWASAN) }\end{array}$} \\
\hline K & 0,146 \\
\hline KP & 0,148 \\
\hline KKE & 0,665 \\
\hline O & $-0,048$ \\
\hline
\end{tabular}

Sumber: Data Primer Diolah, 2016

Berdasarkan tabel hubungan Inner Model diperoleh persamaan model sebagai berikut $: \mathrm{Y}=0,146 \mathrm{~K}+0,148 \mathrm{KP}+0,665 \mathrm{KKE}-0,048 \mathrm{O}$. Nilai Akhir $\mathrm{R}^{2}$ adalah sebagai berikut :

Tabel 4. Nilai R-Square

\begin{tabular}{|l|r|r|}
\hline & $\mathrm{R}^{2}$ & Adjusted $R^{2}$ \\
\hline KEAH & & \\
\hline KECERPROF & & \\
\hline KEP & & \\
\hline OBYEK & & \\
\hline KUPENGAWASAN & 0,698 & 0,646 \\
\hline
\end{tabular}

Sumber: Data Primer Diolah, 2016

Nilai adjusted $\mathrm{R}^{2}$ konstruk Kualitas Pengawasan (KA) adalah 0,646. Artinya konstruk K, KP, KKE, O secara simultan mampu menjelaskan variability konstruk KA sebesar 64,6\%. Karena jumlah variabel eksogen lebih dari dua, maka nilai koefisien determinasi yang digunakan adalah adjusted $R^{2}$ atau nilai pengaruh simultan adalah $64,6 \%$,

\section{Pengujian Hipotesis}

Signifikansi parameter yang diestimasi memberikan informasi yang sangat berguna mengenai hubungan antar variabel penelitian. 
Tabel 5.

Result For Inner Weights

\begin{tabular}{|c|c|c|c|c|c|}
\hline & $\begin{array}{c}\text { Original } \\
\text { Sample } \\
\text { Estimate }\end{array}$ & $\begin{array}{c}\text { Mean of } \\
\text { Subsamples }\end{array}$ & $\begin{array}{c}\text { Standard } \\
\text { Error }\end{array}$ & T-Statistics & P Values \\
\hline K & 0.105 & 0.119 & 0.120 & 0.872 & 0.384 \\
\hline KP & -0.061 & -0.061 & 0.134 & 0.456 & 0.648 \\
\hline KKE & 0.502 & 0.509 & 0.130 & $3.848^{*}$ & 0.000 \\
\hline O & 0.319 & 0.312 & 0.119 & $2.670^{*}$ & 0.008 \\
\hline
\end{tabular}

Keterangan : * = nilai t statistik > t tabel (signifikansi $5 \%=1,664)$

Sumber: Pengolahan data dengan PLS, 2016

Dasar yang digunakan dalam menguji hipotesis adalah nilai yang terdapat pada output result for inner weight. Tabel 1 memberikan output estimasi untuk pengujian model struktural.

\section{HASIL DAN PEMBAHASAN}

\section{Pengaruh obyektivitas terhadap kualitas pengawasan.}

Berdasarkan hasil perhitungan statistic maka dapat disimpulkan bahwa obyektivitas berpengaruh positif dan signifikan terhadap kualitas pengawasan. Positif dapat terlihat dari nilai koefisien jalur sebesar 0, 319 dan dinyatakan signifikan karena dilihat dari nilai t-statistic yang lebih besar dari t tabel $(1,664)$ yakni sebesar 2,670. Hal ini berarti secara keseluruhan tingkat obyektivitas auditor yang bekerja di Inspektorat Pemerintah Propinsi Jawa Tengah dan Kabupaten/kota se karesidenan Semarang termasuk kedalam kategori tinggi. Dengan tingginya tingkat obyektivitas auditor, maka auditor Inspektorat Pemerintah Propinsi Jawa Tengah dan Kabupaten/kota se karesidenan Semarang bersikap obyektif dalam melaksanakan tugas pengawasan.

\section{Pengaruh keahlian terhadap kualitas pengawasan.}

Berdasarkan hasil perhitungan statistik, dapat disimpulkan bahwa keahlian dapat berpengaruh positif tetapi tidak signifikan terhadap kualitas pengawasan. Positif dapat terlihat dari nilai koefisien jalur sebesar 0,105 dan dinyatakan tidak signifikan karena dilihat dari nilai $t$-statistic yang lebih kecil dari 1,664 yakni sebesar 0,872. Secara keseluruhan tingkat keahlian pengawas yang bekerja di Inspektorat Pemerintah Propinsi Jawa Tengah dan Kabupaten/kota se karesidenan Semarang termasuk kedalam kategori rendah. Dengan rendahnya tingkat keahlian auditor, maka 
auditor Inspektorat Pemerintah Propinsi Jawa Tengah dan Kabupaten/kota se karesidenan Semarang kurang ahli dalam melaksanakan tugas pengawasan. Dengan mengikuti program peningkatan keahlian diharapkan akan menghasilkan pengawasan yang berkualitas. Penelitian ini tidak mendukung penelian sukriah, et al (2009) yang menemukan bahwa keahlian seorang auditor berpengaruh positif terhadap kualitas hasil pemeriksaan.

\section{Pengaruh kecermatan profesional terhadap kualitas pengawasan.}

Berdasarkan hasil perhitungan statistik, dapat disimpulkan bahwa kecermatan profesional tidak berpengaruh positif terhadap kualitas pengawasan. Tidak berpengaruh karena dapat dilihat dari nilai koefisien jalur sebesar -0,061dan dinyatakan tidak signifikan karena dilihat dari nilai t-statistic yang lebih kecil dari t tabel $(1,664)$ yakni sebesar 0,456. Hal ini berarti secara keseluruhan tingkat kecermatan profesional auditor yang bekerja di Inspektorat Pemerintah Propinsi Jawa Tengah dan Kabupaten/kota se karesidenan Semarang termasuk kedalam kategori rendah. Dengan rendahnya tingkat kecermatan profesional auditor, maka auditor Inspektorat Pemerintah Propinsi Jawa Tengah dan Kabupaten/kota se karesidenan Semarang kurang cermat dalam melaksanakan tugas audit.

\section{Pengaruh kepatuhan pada kode etik terhadap kualitas audit.}

Berdasarkan hasil perhitungan statistik, dapat disimpulkan bahwa kepatuhan pada kode etik dapat berpengaruh positif dan signifikan terhadap kualitas pengawasan. Positif dapat terlihat dari nilai koefisien jalur sebesar 0,502 dan dinyatakan signifikan karena dilihat dari nilai $t$-statistic yang lebih besar dari t tabel $(1,664)$ yakni sebesar 3,848. Secara keseluruhan tingkat kepatuhan pada kode etik auditor yang bekerja di Inspektorat Pemerintah Propinsi Jawa Tengah dan Kabupaten/kota se karesidenan Semarang termasuk kedalam kategori tinggi. Auditor yang professional dalam melaksanakan pekerjaan dengan didukung dengan adanya sikap kepatuhan pada kode etik akan dapat meningkatkan kualitas audit. Semakin tinggi kepatuhan pada kode etik yang dimiliki oleh seorang auditor dalam melaksanakan profesinya, maka akan semakin meningkat kualitas audit yang dihasilkan. Begitu pula sebaliknya, semakin rendah kepatuhan pada kode etik auditor, maka semakin rendah kualitas audit yang dihasilkan. Dengan meningkatnya kualitas audit yang dihasilkan, maka kepercayaan masyarakat terhadap audiorakan meningkat. 


\section{KESIMPULAN DAN SARAN}

\section{Simpulan}

Berdasarkan pembahasan hasil penelitian, maka dapat ditarik kesimpulan bahwa

1. Secara simultan obyektifitas, keahlian, kecermatan profesional dan kepatuhan pada kode etik secara bersama berpengaruh signifikan terhadap kualitas auditor.

2. Secara parsial obyektivitas dan kepatuhan pada kode etik berpengaruh signifikan terhadap kualitas audit. Keahlian dan kecermatan profesional tidak berpengaruh terhadap kualitas audit sehingga hipotesis 2 dan 3 ditolak yaitu kecermatan profesional berpengaruh positif terhadap kualitas audit.

\section{Saran}

Dalam penelitian ini terdapat keterbatasan yang mempengaruhi hasil penelitian yaitu kuesioner yang digunakan kurang tepat untuk tolok ukur kinerja pegawai pada instansi terkait. Penelitian selanjutnya dapat menggunakan metode yang lain atau dapat memastikan pihak responden bersedia untuk bekerja sama.

Berdasarkan hasil penelitian yang telah dilakukan maka peneliti mengajukan saran yaitu supaya penelitian selanjutnya sebaiknya melakukan penelitian dengan menggunakan metode wawancara langsung untuk mengumpulkan data penelitian agar dapat mengurangi adanya kelemahan terkait internal validity serta memperluas objek penelitian, tidak hanya pada aparat inspektorat kabupaten/kota se-karesidenan saja sehingga hasilnya dapat digeneralisasi.

\section{DAFTAR PUSTAKA}

Arianti, Komang Pariardi, Sujana, Edy dan Putra, Made Pradana Adi (2014). Pengaruh Integritas, Obyektivitas, dan Akuntabilitas Terhadap Kualitas Audit di Pemerintah Daerah (studi pada inspektorat kabupaten buleleng). e-Journal S1 Ak Universitas Pendidikan Ganesha Jurusan Akuntansi S1 (Vol: 2 No: 1 Tahun 2014)

Elder. J. R, Beasley. S.M, Arens, A.A., Jusuf.A.A. 2013. Auditing and Assurance Services. An Integrated Approach 14th Edition (ebook)

Ghozali, I. 2012. Struktural Equation Modeling Metode Alternatif dengan Partial Least Square.versi 3.0 BP Undip. Semarang

Lubis, Haslinda (2009). Pengaruh Keahlian, Independensi, Kecermatan Profesional, dan Kepatuhan pada Kode Etik terhadap Kualitas Auditor pada Inspektorat Propinsi Sumatra Utara. Tesis Sekolah Pasca Sarjana Universitas Sumatra Utara Medan.

Mabruri, Havidz dan Winarna, Jaka (2010). Analisis Faktor-Faktor Yang 
Mempengaruhi Kualitas Hasil Audit di Lingkungan Pemerintah Daerah.SNA XIII. Purwokerto.

Mardiasmo. 2005. Akuntansi Sektor Publik Edisi 2. Penerbit Andi. Yogyakarta

Messier, F.W., S.M. Glover, dan F.D. Prawitt. 2014. Jasa Audit dan Assurance: Suatu Pendekatan Sistematis. Diterjemahkan oleh Priantinah, D., Puspitasari, N. Edisi 8 Buku 2. Penerbit Salemba Empat. Jakarta

Peraturan Gubernur Jawa Tengah Nomor 82 TAHUN 2008 Tentang Penjabaran Tugas Pokok, Fungsi Dan Tata Kerja Inspektorat Provinsi Jawa Tengah.

Peraturan Menteri Negara Pendayagunaan Aparatur Negara nomor PER/05/M.PAN/03/2008. Tentang Standar Audit Aparat Pengawasan Intern Pemerintah. Jakarta.

Peraturan Menteri Negara Pendayagunaan Aparatur Negara nomor. Per/ 04/ M. Pan/ 03/ 2008 Tentang “Kode Etik Aparat Pengawasan Intern Pemerintah".

Pusbin JFA. --. Profil Jabatan Fungsional Auditor (JFA) Aparat Pengawasan Internal Pemerintah (APIP). Jakarta.

Pusdiklatwas BPKP. 2005. Modul Diklat Pembentukan Auditor Ahli: Kode Etik Dan Standar Audit. Bogor.

Sukriah, Ika. Akram dan Biana Adha Inapty. 2009. Pengaruh Pengalaman Kerja, Independensi,Obyektifitas, Integritas dan Kompetensi Terhadap Kualitas Hasil Pemeriksaan. SNA XII. 